\title{
ONLINE DISPUTE RESOLUTION (ODR): A SOLUÇÃO DE CONFLITOS E AS NOVAS TECNOLOGIAS
}

\author{
ONLINE DISPUTE RESOLUTION (ODR): CONFLICT \\ RESOLUTION AND NEW TECHNOLOGIES
}

\author{
Gabriela Vasconcelos Lima ${ }^{1}$ \\ Gustavo Raposo Pereira Feitosa ${ }^{1}$
}

\section{Recebido em: 30/09/ 2016 Aceito em: 22/12/2016 \\ gvasconceloslima@gmail.com gfeitosa@unifor.br}

Resumo: A ascensão do uso das novas tecnologias da informação e comunicação (TICs) impõe transformações na forma como o Sistema de Justiça atua e como as normas jurídicas incidem sobre os conflitos. O avanço de um amplo conjunto de novas relações construídas em rede, mediada por ferramentas comunicacionais, associado ao desafio de encontrar alternativas ao déficit constante na resposta jurisdicional tradicional para os litígios evidencia a importância dos modelos de solução de conflitos online. Assim, o presente artigo tem como objetivo apresentar uma revisão da literatura científica acerca dos modelos de Online Dispute Resolution (ODR), a fim de oferecer um ponto de partida para os pesquisadores da área e para as iniciativas engendradas para o Sistema de Justiça brasileiro. A leitura aprofundada e sistemática dos estudos realizados na Europa e nos EUA permite expor perspectivas e desafios para o futuro da ODR. Dividiu-se, assim, o trabalho em três tópicos: história e evolução das ferramentas de ODR; definição, aspectos relevantes, vantagens e dificuldades da adoção de ODRs como método de solução de conflitos; e por fim, perspectivas e desafios para o futuro dos métodos de solução de conflitos em rede. Conclui-se que o maior controle das partes sobre a tomada de decisão e a comunicação assíncrona, característica peculiar às ODRs, são aspectos únicos e representam potencial importante de mudança de cultura e empoderamento social para que os indivíduos passem a buscar a solução de seus conflitos por meio de procedimentos dialogados.

Palavras-chave: Online Dispute Resolution. Métodos Adequados de Solução de Conflitos. Virtualização. Poder Judiciário. Novas tecnologias da comunicação e da informação.

\begin{abstract}
The growth in usage of the new Information and Communication Technologies (ICTs) remodels the way the Justice System works and how laws impact on conflict. The development of a wide range of new kinds of relationship built online, measured by communicational tools, related to the challenge of finding different solutions to the permanent deficit on the traditional judicial response to disputes, highlights the relevance of Online Dispute Resolution (ODR). Therefore, this paper aims to present a national and international scientific literature review on the models of Online Dispute Resolution, in order to offer a solid starting line from where researchers and developing ODR tools on the Brazilian Judiciary Power can progress. The deep and systematic Reading of the studies from Europe and America allows us to comment on the perspectives and challenges for the futuro of ODR. Thus, the paper was divided into three different topics: history and evolution of ODR; definition, relevant aspects, advantages and disadvantages on the adoption of ODR as a tool for conflict resolution; and perspectives and challenges for the future of ODR. At the end of the research we came to the conclusion that the control the involved parties have on the decision-making process and the asynchronous communication combined are exclusive aspects of ODR and represent an important potential for a cultural change and for the empowerment of individuals, who will hopefully learn to try to solve their own problems through negotiation and dialogue.
\end{abstract}

Keywords: Online Dispute Resolution. Alternative Dispute Resolution. Virtualization. Justice System

\section{INTRODUÇÃO}

\footnotetext{
${ }^{1}$ Universidade de Fortaleza - UNIFOR - Fortaleza - Ceará - Brasil
} 
A Reforma do Judiciário de 2004 (EC45) trouxe como uma de suas mais importantes inovações a criação do Conselho Nacional de Justiça $(\mathrm{CNJ})$, responsável pelo controle administrativo do Poder Judiciário e pelo planejamento das políticas públicas para o Sistema de Justiça. Como formulador de políticas, o CNJ precisa amparar suas decisões em diagnósticos e análises resultantes de relatórios estatísticos e de comunicação de informações remetidas pelos órgãos judiciários de todo o país.

A partir das informações estatísticas e do panorama traçado das atividades do Poder Judiciário nacional, o CNJ tem trabalhado na formulação de uma série de políticas públicas a fim de solucionar os problemas identificados e aprimorar a prestação jurisdicional. Pode-se citar dentre as ações implementadas pelo órgão, o incentivo à adoção dos "Métodos Adequados de Solução de Conflitos" (MASCs), tais como mediação e conciliação; a virtualização do Poder Judiciário; a criação de metas orientadas para redução do estoque de processos, dentre outras.

Sobressai em meio às iniciativas do Conselho a valorização do uso das novas tecnologias em todas as esferas de atuação da função jurisdicional. Num contexto de transformações da sociabilidade geradas por inovações tecnológicas e pelo intenso uso de comunicação em tempo real, percebeu-se a necessidade de reavaliação das formas atuais de solução de conflitos e de sua atualização para se adequarem à realidade contemporânea. A quase onipresença das comunicações em rede mediada pelos dispositivos móveis como smartphones e tablets repercutem diretamente na forma como as pessoas se comunicam, interagem, fazem negócios e convivem.

A ascensão do uso das novas tecnologias da informação e comunicação (TICs) impõe transformações basilares na forma como o Sistema de Justiça funciona e como as normas jurídicas incidem sobre o chamado ciberespaço. Não se pode, contudo, medir exatamente qual o impacto destas tecnologias na autoridade e no poder dos Estados, enquanto órgãos responsáveis pela elaboração, execução e fiscalização das leis. Estas transformações atingem níveis ainda mais básicos, pois redefinem o próprio conceito de lei e sua formação e evolução² (KATSH, 2006).

O uso massivo e difuso destas novas formas de comunicação criou um cenário propício para o surgimento do modelo de Online Dispute Resolution (ODR) (ou, em português, Métodos de Solução de Conflitos em Rede) em países como EUA e Canadá e a importação do conceito para o Brasil. No Brasil, o conceito ganhou destaque no âmbito do Sistema de Justiça apenas em 2016, como forma não só de ampliar e democratizar a adoção dos Métodos Adequados de Solução de Conflitos, como também de os unir às ações de virtualização ${ }^{3}$ do Poder Judiciário.

A chamada ODR consiste na utilização da tecnologia da informação e da comunicação no processo de solução de conflitos, seja na totalidade do procedimento ou somente em parte deste. Dentre os procedimentos que podem adotar o modelo da ODRs, estão a arbitragem, a mediação, a conciliação ou a negociação, que o fazem por intermédio de ferramentas automatizadas (total ou parcialmente). Essa solução representa uma forma de virtualização plena, em que um procedimento

\footnotetext{
${ }^{2}$ Para mais sobre o impacto da internet na formulação legislativa: LESSIG, Lawrence (2006).

${ }^{3} \mathrm{O}$ conceito de virtualização não deve ser entendido aqui de forma restrita, enquanto ao processo eletrônico, mas deve representar toda a transposição da estrutura burocrática judiciária para o ciberespaço. Sobre este assunto: FREIRE, 2014; LÉVY, 2011; CASTELLS, 2003; LEMOS, 2007.
} 
nasce e morre no ambiente virtual, sem necessidade de passar por etapas presenciais ou no espaço forense.

O presente artigo tem como objetivo apresentar uma revisão da literatura científica acerca dos modelos de Online Dispute Resolution, a fim de oferecer um ponto de partida sólido para os pesquisadores da área e para as iniciativas engendradas no âmbito do Sistema de Justiça. Ao mesmo tempo, a leitura aprofundada e sistemática dos estudos realizados na Europa e nos EUA permitem expor perspectivas e desafios para o futuro da ODR. Dividiu-se, assim, o trabalho em três tópicos que abordam as seguintes temáticas: história e evolução das ferramentas de ODR; definição, aspectos relevantes, vantagens e dificuldades da adoção de ODRs como método de solução de conflitos; e por fim, perspectivas e desafios para o futuro dos métodos de solução de conflitos em rede.

\section{HISTÓRIA E EVOLUÇÃO DAS FERRAMENTAS DE ODR}

As formas de solução de conflitos online começaram a ser pensadas no início dos anos 1990, apesar da invenção da internet datar do fim dos anos 1960 (KATSH; RIFKIN, 2001; RULE, 2002). Tal fato decorre de uma série de fatores históricos, que explicam a falta de necessidade de mecanismos desta natureza até então. Em 1969, a Advanced Research Projects Agency (ARPA) criou uma rede de computadores denominada Arpanet. A agência criadora da rede foi formada com o objetivo de mobilizar recursos de pesquisa, para buscar soluções tecnológicas que garantissem a superioridade dos Estados Unidos (EUA) sobre a União Soviética, num período de animosidades decorrentes da Guerra Fria (CASTELLS, 2003; HAUBEN; HAUBEN, 1997; LÉVY, 1999; COHEN-ALMAGOR, 2013).

Os primeiros pontos de Internet, em 1969, podiam ser encontrados na Universidade da Califórnia em Los Angeles, na Universidade da Califórnia em Santa Bárbara, no Instituto de Pesquisa de Stanford e na Universidade de Utah. Dois anos depois, em 1971, a rede havia sido expandida para 15 pontos, presentes também, em sua maioria, em Universidades e centros de pesquisa (KLEINROCK, 2010). Com a primeira fase do projeto estabilizada e bem desenvolvida, o segundo passo consistiu em conectar a Arpanet a outras redes também controladas pela ARPA (PRNET e SATNET), o que Castells (2003, p. 21) chama de "rede de redes".

[...] a Arpanet, a principal fonte do que viria a ser afinal a Internet, não foi uma consequência fortuita de um programa de pesquisa que corria em paralelo. Foi prefigurada, deliberadamente projetada e subsequentemente administrada por um grupo determinado de cientistas da computação que compartilhavam uma missão que pouco tinha a ver com estratégia militar. Enraizou-se num sonho científico de transformar o mundo através da comunicação por computador [...].

Dentre os requisitos exigidos pelos envolvidos na pesquisa estava um baixo tempo de resposta na comunicação entre computadores, que se "proporcionasse a sensação que os indivíduos 
estariam conectados em computadores que compartilham o mesmo tempo-espaço, mesmo que os computadores utilizados estejam a milhares de quilômetros de distância" (tradução livre) ${ }^{4}$. Essa funcionalidade é essencial ainda hoje para possibilitar a comunicação em tempo real e mais especificamente para viabilizar a existência de ferramentas de ODR de resposta mais rápida e eficaz.

Em 1975, a Arpanet foi entregue à Defense Communication Agency, para que ela fosse distribuída igualmente a todos os ramos das forças armadas estadunidenses, que a transformou, em 1983, em MILNET, uma rede mais segura, dedicada somente a operações e comunicação militares. A antiga Arpanet passou, então, a ser dedicada exclusivamente à pesquisa e foi renomeada para ARPA-INTERNET. No ano seguinte, a National Science Foundation (NSF) montou sua própria rede de computadores, a nomeou NSFNET e passou a utilizar, em 1988, a estrutura física da Arpanet como base (CASTELLS, 2003; LEINER at al., 1997).

Após 21 anos em operação, em 1990, a Arpanet, já obsoleta, foi desativada, o que tirou do ambiente militar o controle sobre a rede. Então, o governo dos Estados Unidos transferiu sua administração para a National Science Foundation (NSF). A NSF entendia a necessidade de uma rede estruturada e extensa que suportasse toda a comunidade acadêmica e de pesquisa, além da necessidade da rede se expandir de forma independente do financiamento estatal (LEINER at al., 1997). A NSF controlou a internet até 1995, quando foi extinta e a operação da internet foi liberada para a iniciativa privada, o que impulsionou seu crescimento e popularização. Castells (2003, p. 15) explica que

[...] o que tornou isso possível foi o projeto original da Arpanet, baseado numa arquitetura em múltiplas camadas, descentralizada, e protocolos de comunicação abertos. [...] Mas a Arpanet não foi a única fonte da Internet tal como a conhecemos hoje. O formato atual da Internet é também o resultado de uma tradição de base de formação de redes de computadores.

O momento em que a NSF, em 1992, abriu a Internet para transações comerciais foi chave para a evolução no mundo dos MASCs, na medida em que gerou uma série de novos modelos de interações (CASTELLS, 2003). Consequentemente, uma série de novos modelos de conflitos foram gerados, entre usuários que, por terem como base para sua interação o ciberespaço, restam impossibilitados ou encontram dificuldades em participar em qualquer processo de solução de conflito face to face $(\mathrm{F} 2 \mathrm{~F})^{5}$. Assim, tornou-se fundamental a concepção de um formato de solução de conflitos que atuasse no mesmo ambiente onde os conflitos foram originados (KATSH; RIFKIN, 2001; RULE, 2002).

A internet passou por inúmeras mudanças e evoluções ao longo de sua história, e continuará a mudar, na medida em que a indústria da computação evoluir. Tais modernizações permitem que se

\footnotetext{
${ }^{4}$ Original: "Yet another requirement we introduced was for the network to provide an experience as if one were connected to a local timeshared computer even if that computer was sitting thousands of miles across the network" (KLEINROCK, 2010, online).

${ }^{5} \mathrm{O}$ termo face-to-face ou F2F pode ser traduzido livremente como "ao vivo" ou "cara-a-cara", significando fora do ciberespaço.
} 
crie um novo paradigma de comunicação entre computadores, que passam a alterar, ainda mais, a forma como a sociedade se comporta frente tais inovações. A questão mais importante, portanto, centra-se em como o processo de evolução constante será encarado, no futuro, pela própria indústria e pela sociedade (LEINER et al., 1997).

Antes dos anos de 1990, a baixa difusão do uso da internet, restrita majoritariamente a militares e acadêmicos, reduzia seu impacto potencial na alteração das relações entre as pessoas e na geração de novos conflitos. Cidadãos alheios a estes setores sociais desconheciam a utilidade na internet, uma vez que esta, de fato, possuía funcionalidades extremamente limitadas. A restrição ao uso da Internet para fins comerciais até 1992, pela NSF, que gerenciou o uso da internet por 10 anos (de 1985 a 1995), fortalecia o cenário de contenção. Mesmo que um indivíduo tivesse acesso à rede e soubesse como usá-la, ele não poderia comercializar bens ou serviços online, o que restringiu as possibilidades de conflitos originados em rede (KATSH, 2012; LEINER at. al, 1997).

Os contextos nos quais os conflitos online se inserem também evoluíram e se diversificaram na medida em que o próprio uso da internet avançou e se transformou. No início dos anos 90, por exemplo, a base de usuários da internet era composta majoritariamente por alunos e funcionários universitários, pois este era o segmento que possuía acesso. A maior parte dos conflitos decorrentes das relações baseadas na internet, possuíam membros dessa comunidade como partes envolvidas (KATSH, 2012). Esse momento na evolução dos métodos de ODR teve duração, segundo Katsh e Rifkin (2001), até 1995, pois, de acordo com os autores, em decorrência do uso específico da Internet por usuários vinculados a universidades e centros de pesquisa, os tipos de conflitos eram muito específicos.

No entanto, com a criação dos provedores de serviço de internet (Internet Service Providers ISPs), em 1992, tornou-se possível a inclusão ampla de qualquer pessoa e não só aquele que possuísse afiliação com universidades. Assim, formou-se uma base de usuários maior e mais diversificada (CASTELLS, 2003). Desde esta abertura da rede, já se percebeu a necessidade da criação de algum método de solução de conflitos entre os ISPs e seus usuários. Com este objetivo, o National Centre for Automated Information Research (NCAIR) em colaboração com o Cyberspace Law Institute (CLI) criou o Virtual Magistrate (VM), o primeiro software de arbitragem em rede, baseado na Universidade de Villanova, na Filadélfia. Esta solução em ODR lidava com conflitos envolvendo casos de difamação, desrespeito a direitos autorais, fraude e apropriação ilegal de segredos empresariais. O projeto somente gerou uma decisão: Tierney vs Email America, na qual ele obrigou a America Online ( $A O L)$ a desativar uma propaganda oferecendo milhões de endereços de email que poderiam ser utilizados para envio de mensagens em massa (CORTÉS, 2011; BENYEKHLEF; GÉLINAS, 2005; GELLMAN, 1996; GOLDSMITH; LESSIG, 1996).

Benyekhlef e Gélinas (2005) atribuem o insucesso da plataforma à limitação de seu escopo, que se restringia aos conflitos originários de relações firmadas online. Além disso, os conflitos que envolvessem relacionamentos prioritariamente econômicos, que são, na opinião dos autores, os mais apropriados à arbitragem, não poderiam ser submetidos ao VM. Ainda sobre o restrito escopo de ação do VM, os autores entendem que os casos de difamação, desrespeito a direitos autorais, fraude e apropriação ilegal de segredos empresariais, que eram da competência do VM, seriam melhor 
solucionados por procedimento de mediação. Os autores consideram ainda que o tipo de software utilizado era muito primário para a forma de solução de conflitos adotada, dependendo majoritariamente de e-mails não seguros. Finalmente, dentre as fraquezas encontradas na plataforma, deve-se mencionar que apesar do ISP poder incluir uma cláusula arbitral em seu contrato, vinculando tanto a si próprio quanto a parte contratante ao procedimento arbitral, intermediado pelo VM, caso algum conflito surgisse, o resultado deste procedimento possuiria alguns efeitos contratuais vinculantes, mas não poderia ser considerado título executivo para fins jurídicos ${ }^{6}$.

Aliada à abertura da rede, em 1995, Katsh e Rifkin (2001) consideram que se inaugura um novo momento na evolução das ferramentas de ODR, que coincide com a expansão e popularização da Internet, tendo sua transição para um novo momento a partir de 1998. Neste ano Jeff Bezos lançou a Amazon ${ }^{7}$, seguido por Pierre Omidyar, que lançou o eBay ${ }^{8}$ no mês seguinte, ampliando o leque de utilidades da internet e, consequentemente, o leque de possibilidades de conflito, que se estende seguindo a diversificação da natureza das relações interpessoais (KATSH, 2012). Dessa forma,

[...] os envolvidos e o interventores, que estava abertos à utilização da tecnologia estavam, na maior parte das vezes, utilizando-se da mesma forma de comunicação por meio da qual seu conflito teve início para buscar sua solução, e o impulso de utilizar esses canais e de focar em comunicação textual era compreensível: frequentemente é mais eficiente (permitindo participação assíncrona à conveniência das partes), possui maior custo benefício (não requerendo pagamento de ligações telefônicas ou viagens), e é normalmente a única opção realista (quando um conflitos trans-jurisdicional de penqueno ou nenhum valor pecuniário). (WING; RAINEY, 2012, p. 41. Tradução livre) ${ }^{9}$

\footnotetext{
${ }^{6}$ Para mais informações sobre a plataforma Virtual Magistrate: GELLMAN, 1996. Disponível em: <http://www.umass.edu/dispute/ncair/gellman.htm> Acesso em: 09 abr. 2016.; GOLDSMITH; LESSIG, 1996. Disponível em: <http://www.umass.edu/dispute/ncair/groundvm.htm> Acesso em: 09 abr. 2016.

${ }^{7}$ A Amazon.com funciona como plataforma de intermediação de vendas, possibiliando a comunicação entre vendedores físicos, empresas e consumidores. O fundador a Amazon.com, Jeff Bezos, fundou a empresa em julho de 1995. A missão da empresa é ser a instituição mais centrada no consumidor do mundo, considerando como seus quatro principais consumidores: o consumidor final, os vendedores, as empresas e os criadores de conteúdo. Para mais informações: <http://phx.corporate-ir.net/phoenix.zhtml?c=97664\&p=irol-faq > Acesso em: 09 abr. 2016

${ }^{8}$ O eBay é uma plataforma, fundada em 1995, que atua na intermediação de compras e vendas entre indivíduos, independente da localização dos envolvidos na transação, dos produtos e outros aspectos da transação. Hoje, a plataforma atende 162 milhões de compradores e abriga 800 milhões de ofertas, espalhados pelo globo. (WHO WE ARE, online. Disponível em: <https://www.ebayinc.com/our-company/who-we-are/>. Acesso em: 25 abr. 2016)

${ }^{9}$ Original: [...] parties and interveners who were open to using technology were most often using the mode of communication in which they had begun their dispute in order to resolve it, and the impulse to use these channels and to focus on textual communication was understandable: often it is more efficient (allowing asynchronous participation at the convenience of the parties), cost effective (not requiring payment for phone calls or travel), and is often the only realist option (when a cross-jurisdictional dispute of little or no monetary value is involved) (WING; RAINEY, 2012, p. 41).
} 
Percebendo a necessidade de uma ferramenta que facilitasse o tratamento de conflitos envolvendo seus usuários, o eBay pediu que o Center for Information Technology and Dispute Resolution da University of Massachussets Amherst conduzisse um experimento, mediando conflitos envolvendo seus usuários. Em duas semanas, 200 conflitos foram mediados, o que alertou os administradores do site para a necessidade da adoção de um instrumento dessa natureza como política institucional. O site contratou, inicialmente, a start-up ${ }^{10}$ SquareTrade e, anos mais tarde, tomou a responsabilidade por esta ferramenta para si (KATSH, 2012).

Da mesma forma que ocorreu com o eBay, diversos empreendedores perceberam a tendência para a solução de conflitos online e, entre os anos de 1999 e 2000, uma série de start-ups foram criadas e dissolvidas, mas empresas como a SmartSettle e a CyberSettle, permaneceram ativas. A SmartSettle, fundada por Ernest Thiessen, oferece uma plataforma de negociação, para conflitos envolvendo duas ou múltiplas partes. A plataforma dispõe de diferentes pacotes de serviço para casos de baixo valor ou para casos de alto valor pecuniário. A plataforma anuncia ser, em seu site, o sistema líder em negociação online do mundo (SMARTSETTLE, 2016; THIESSEN, FRASER, 2003)

A CyberSettle, criada em 1996, por Charles Brofman, também consiste numa plataforma de facilitação de negociação às cegas, com o diferencial da opção pela facilitação por meio do telefone. Diz-se que a plataforma nasceu do desejo de alcançar algo que se acreditava impossível: negociar casos de maneira justa e rápida. De acordo com estudos de caso sobre a plataforma, quase 200.000 transações foram realizadas, o que representa $\$ 1.457 .299 .751,00$ em acordos. A plataforma foi adotada pela cidade de Nova lorque, que economizou \$11.6 milhões durante o primeiro ano de utilização, negociando 66\% dos casos em que figurava como parte, em 30 dias (LEVIN, 2008).

Em meados dos anos 2010, percebe-se novamente uma tendência para as soluções online de disputa. Esse novo movimento diferiu das iniciativas ocorridas nos anos 2000, na medida em ganharam protagonismo as propostas governamentais, a exemplo da União Europeia, de órgãos do Poder Judiciário estadunidense, como a National Mediation Board (NMB) e o Office of Government Information Services (OGIS) (KATSH, 2012) No caso brasileiro, o Executivo Federal brasileiro criou a plataforma consumidor.gov.br e Tribunal de Justiça do Rio de Janeiro implantou o aplicativo de conciliação pré-processual, todos adotando e promovendo o modelo de ODR como um instrumento de solução de conflitos.

Percebe-se clara relação com as fases de evolução dos MASCs identificadas nos Estados Unidos (SANDER, 2000). A primeira fase, intitulada por Sander (2000) como "let a thousand flowers bloom", traduzido por Sales (2012) como "deixe as mil flores desabrocharem", caracterizou-se pela efervescência de novas experiências com MASCs. Num segundo momento, quando inúmeras iniciativas privadas haviam surgido, passou-se à preocupação de quais destas possuíam qualidade suficiente para permanecer no mercado. Intitulou-se essa fase de "Cautions and Caveats" (ou

\footnotetext{
${ }^{10}$ Uma start-up consiste num "grupo de pessoas à procura de um modelo de negócios repetível e escalável, trabalhando em condições de extrema incerteza". Mais informações sobre o conceito de start-ups disponíveis em: < http://exame.abril.com.br/pme/noticias/o-que-e-uma-startup> Acesso em: 12 abr. 2016.
} 
"Cuidados e Advertências"). Ao terceiro momento, chamou-se de "Institucionalização". Este é o momento pelo qual as ODR passam ao longo dos anos 2010. Percebe-se uma forte onda de adoção destes mecanismos pelos Estados, como forma de fazer a prestação jurisdicional de maneira mais eficaz e eficiente.

Com a evolução das formas de ODR, uma série de questões jurídicas começaram a surgir decorrentes da natureza dos conflitos por ela tratados, uma vez que estes envolviam, em sua maioria, relações entre indivíduos de locais diversos, interagindo online. Questões como, qual seria a comarca (em determinados casos, qual país) competente no caso de conflitos decorrentes de relações online, ou, como agir na impossibilidade de uma das partes se deslocarem até a jurisdição), se tornaram relevantes para que se pudesse continuar a evoluir. No entanto, até meados da década de 2010, a necessidade de abordar estes questionamentos vinha sendo adiada, uma vez que,

A comunicação rápida em rede e a capacidade de processamento de informações [...] abriu, de fato, oportunidades para abordagens e respostas criativas para a solução de problemas em casos que não chegaram aos tribunais. Em outras palavras, muitas das mesmas forças que contribuíram para a origem dos conflitos, poderiam também ser empregadas em sua solução. (KATSH, 2012, p. 24. Tradução livre) ${ }^{11}$

Nesse ínterim, o eBay ${ }^{12}$ reportou solução de mais de 60 milhões de conflitos decorrentes de relações consumeristas mediadas pelo site até o ano de 2010, evidenciando, assim, não só o alto número de conflitos derivados de relações online (especificamente, das interações intermediadas pela plataforma), mas sobretudo, o poder dos próprios envolvidos os solucionarem.

Se se considerar que todas as formas de solução de disputas são, em variados graus, exercícios de gerenciamento de comunicação entre partes durante um conflito ou no processo de solução deste (WING; RAINEY, 2012), pode-se dizer que, na verdade, o âmbito de origem do conflito (online ou offline) não deveria determinar o direcionamento das pesquisas sobre sua solução, uma vez que há uma série de conflitos originados no mundo físico que pode ser submetido à uma forma de ODR. Dessa forma, o desafio deve ser encontrar um leque de soluções em ODR que possibilitem a solução de conflitos independente da sua origem. Assim, além de (e mais que) discutir os tipos de conflitos que podem se submeter a resolução online, deve-se focar em buscar ferramentas que garantam confiança, transparência e tratamento adequado para uma variedade de conflitos (KATSH, 2012).

Outro aspecto determinante para a evolução das formas de ODR foi a evolução da chamada Web 1.0 para a Web 2.0, conceituada por O'Reilly e Battelle (2009) como uma cultura em que os

\footnotetext{
${ }^{11}$ Original: the network's rapid communication and information processing capabilities [...] did open up oppotunities for creative approaches and responses to problem solving for cases that did not go to court. In other words, many of the same forces that contributed to disputes could also be employed to resolve disputes" (KATSH, 2012, p. 24)

${ }^{12}$ Mais sobre a ferramenta de ODR prórpia do eBay em: EDWARDS; THEUNISSEN, 2006; KATSH; RIFKIN, 2001; GAITENBY, 2000.
} 
softwares são criados para incentivar a criação de inteligência coletiva, de forma que melhorem a medida que avance a utilização pelo público e cresçam as contribuições dos usuários. A Internet passou de um ambiente no qual o conteúdo era gerado pelas empresas e sites e oferecido para consumo, para uma plataforma colaborativa, em que os usuários simultaneamente produzem e consomem conteúdo, possuem voz e interagem entre si e com a rede de forma proativa, popularizando sites em que se pode comentar e avaliar vendedores e provedores de serviços, além de sites que possibilitam denúncias e reclamações de clientes sobre empresas contratadas.

Percebeu-se, no setor comercial, que aspectos além de preço e conveniência eram relevantes no relacionamento entre cliente e empresa, tais como confiança e baixo risco na transação. Nesse sentido, a adoção de ferramentas de solução de conflitos online mostra seu valor não só da forma mais óbvia: solucionando conflitos, mas principalmente como parte do esforço institucional de construção de confiança. Assim, o usuário tem a consciência de que, caso haja algum problema na sua transação, ele será ouvido e respondido (KATSH, 2012). Viñals (2014, p. 398) reitera que as ODR:

As transformações na Internet levaram, assim, a um amplo e rápido processo de mudança dos modos de interação entre usuários e, consequentemente, nos conflitos e em suas formas de solução. Criaram-se, dessa forma, os métodos de ODR, para responder às necessidades dos usuários da Internet de gerir seus conflitos e aprimorar as formas de relação entre empresas e consumidores nas transações virtuais. Tais mutações não passariam ao largo do Sistema de Justiça, em especial diante da chegada das novas conflituosidades no espaço das cortes. O cenário da modernidade líquida caracterizado por Bauman (2003) oferece aos tribunais e aos múltiplos atores da Justiça grandes desafios e enormes possibilidades. Nesse contexto, o próximo tópico tem como objetivo estudar os conceitos e aspectos relevantes da ODR para a solução de conflitos.

\section{ONLINE DISPUTE RESOLUTION}

A chamada Online Dispute Resolution ou, em português, Resolução de Conflitos em Rede, configura uma forma de solução de conflitos que ocorre total ou parcialmente no ciberespaço (GOODMAN, 2003; KATSH; RIFKIN, 2001; RULE, 2002). Para Pierre Lévy (2000, p. 92) o ciberespaço consiste num "[...] espaço de comunicação aberto pela interconexão mundial dos computadores e das memórias dos computadores". O autor entende, ainda, que a definição de ciberespaço inclui todos os meios eletrônicos de comunicação, como as redes telefônicas clássicas, na medida em que elas transmitem informações de fontes digitais ou destinadas à digitalização. Esse novo meio de transmissão da informação apresentaria a vocação para: 
[...] colocar em sinergia e interfacear todos os dispositivos de criação de informações, de gravação, de comunicação e de simulação. A perspectiva da digitalização geral das informações provavelmente tornará o ciberespaço o principal canal de comunicação e suporte de memória da humanidade a partir do próximo século. (LÉVY, 2000, p. 92-93)

Estas palavras proferidas por Lévy (2000) inicialmente no final do século XX, anteciparam a expansão e a quase onipresença da internet no cotidiano global, não só para a vida dos indivíduos, mas das empresas. Seja qual for seu porte ou produto oferecido, estas passam a oferecer uma série de serviços, antes prestados somente em meio físico, e agora, em versões online.

Dada a influência e as mudanças operadas pelo modelo crescentemente virtual das relações humanas, percebeu-se a necessidade de adaptar as formas tradicionais de solução de conflitos, em especial por suas desvantagens financeiras e de tempo, bem como por suas limitações de jurisdição em casos envolvendo relações virtuais (GOODMAN, 2003; KATSH; RIFKIN, 2001; RULE, 2002). Este novo formato de solução de conflitos em análise pode ser utilizado para gerir tanto conflitos que tiveram sua origem online, tais como os oriundos de relações de consumo em e-commerce, quanto aqueles nascidos de relações offline ou fora do ciberespaço, como conflitos de consumo entre empresas de telefonia e consumidores, por exemplo.

A ascensão do uso das novas tecnologias da informação impõe transformações basilares na forma como o Sistema de Justiça se desenvolve e como a lei se relaciona com o ciberespaço. Não se pode medir exatamente qual o impacto destas tecnologias na autoridade e poder dos Estados, enquanto órgãos responsáveis pela elaboração, execução e fiscalização das leis, contudo estas transformações atingem níveis ainda mais básicos, na medida em que redefinem ou testam o próprio conceito de lei nacional, sua formação, evolução e aplicação (KATSH, 2006; LESSIG, 2006).

A resolução de conflitos em rede concretiza o conceito de virtualização do Poder Judiciário, uma vez que viabiliza que todo o procedimento ocorra de forma virtual e mesmo que em determinadas situações as partes acabem optando por dar continuidade ao procedimento de forma presencial. Não se pode considerar virtualização a simples utilização de instrumentos da tecnologia da informação nas salas de audiência tradicionais e fóruns, tais como vídeo-conferências e computadores, ou mesmo a digitalização dos processos. O avanço na matéria da solução de conflitos online se dá não só no aprimoramento do processo eletrônico para que este passe a se desenvolver de forma cada vez mais virtualizada, mas, e principalmente, na elaboração de todo um novo procedimento para a solução online dos conflitos.

Com a evolução das plataformas de ODR, este formato tenderá a ser uma forma diferenciada de solução de conflitos e, não só uma plataforma na qual se podem realizar os procedimentos tradicionais de forma online (KATSH, 2012). Esta leitura, contraria a interpretação mais restrita dos efeitos renovadores da ODR sobre a forma como se desenvolvem os processos judiciais e os métodos de solução de conflito. Para Cortés (2011, p. 53): 
Os métodos de solução de conflitos podem ser complementados pelas TICs. Refere-se a este processo como ODR, quando ele ocorre majoritariamente online. Isto pode incluir a proposição do procedimento, o agendamento neutro da sessão, os processos de produção de provas, as oitivas, discussões e mesmo a entrega de decisão vinculante. A ODR é simplesmente um meio diferente de se solucionar conflitos, do início ao fim, enquanto ainda respeitando os princípios do devido processo ${ }^{13}$.

A reflexão sobre esse novo procedimento depende diretamente da análise do papel do terceiro imparcial (juiz, mediador ou árbitro). As soluções de conflito em rede se organizam da mesma forma em que se organizam os meios adequados de solução de conflitos (arbitragem, mediação, conciliação e negociação). Os MASCs podem ser graduados entre modelos que concentram maior ou menor controle e poder de intervenção do terceiro imparcial. Nos casos da arbitragem, conciliação e mediação, há a participação do terceiro imparcial, contudo há grande variação quanto à proeminência decisória deste. Na negociação não há atuação de um terceiro e os envolvidos no conflito atuam de modo muito direto na construção da solução. As ODRs se organizam da mesma forma, podendo apresentar plataformas com ou sem atuação de um terceiro no procedimento, conferindo maior ou menor autonomia às partes.

Katsh e Rifkin (2001) denominam a tecnologia no ODR de "quarta parte", afirmando que esta passa a interagir com as partes envolvidas no conflito e o terceiro imparcial (quando presente). As ferramentas tecnológicas melhorariam o processo de solução do conflito e agiriam de forma mais decisiva do que simplesmente transferindo a informação por meio da Internet. Comportar-se-iam como uma verdadeira aliada da terceira parte (árbitro, mediador ou conciliador). A tecnologia escolhida garantiria grande leque de utilidades aptas a facilitar e aprimorar o processo da ODR, como, por exemplo, apresentando e organizando informações, de maneira graficamente amigável ao usuário.

Pode-se argumentar, no entanto, que a utilização da "quarta parte" - aqui entendida como as TICs, que complementariam o procedimento - não se mostra eficaz pela falta de contato entre os envolvidos, na medida em que os isola uns dos outros, bem como do terceiro imparcial. De acordo com Wing e Rainey (2012), um procedimento F2F, como a mediação presencial, por exemplo, facilita a empatia entre as partes, melhora a compreensão da posição oposta e reduz o preconceito. Para Sales (2004, p.17) uma vez que tem como objetivo buscar "laços entre os envolvidos na contenda que possam amenizar a discórdia e facilitar a comunicação. [...] A mediação estimula, por meio do diálogo, o resgate dos objetivos comuns que possam existir entre os indivíduos que estão vivendo o problema". De forma mais crítica, Katsh (2012) posiciona-se afirmando que as soluções F2F, apesar

\footnotetext{
${ }^{13}$ Original: "Dispute resolution methods may be complemented with ICT. The process is referred to as ODR when it is conducted mainly online. This may include the initial filing, the neutral appointment, the evidentiary processes, oral hearings, discussions, and even the rendering of binding decisions. ODR is simply a different medium to resolve disputes, from beginning to end, while still respecting due process principles." (CORTÉS, 2011, p. 53)
} 
de conferirem ao processo uma oportunidade de comunicação rica e flexível, não são completas e nem perfeitas.

Mecanismos de resolução de conflitos online podem adotar ferramentas que variam da negociação à mediação, conforme já afirmado, em softwares projetados com diferentes níveis de automação. Sistemas baseados em negociação, por exemplo, não exigem qualquer tipo de intervenção humana e podem funcionar de forma totalmente automatizada, contando somente com a participação das partes diretamente envolvidas no conflito. Este modelo funciona por meio do envio de propostas ou contrapropostas por intermédio do próprio sistema de ODR. Esse padrão de sistema se mostra apropriado quando o conflito em questão é baseado tão somente na disputa de valores monetários e a obtenção de um acordo para o pagamento de determinado valor mostra-se o objetivo principal.

Cortés (2011) enumera como vantagens da utilização das ODR a economia financeira e de tempo, a conveniência do procedimento, os benefícios em comparação ao litígio e o controle das partes sobre o resultado. Quanto às dificuldades do processo, o autor menciona a falta de contato F2F, os problemas tecnológicos que podem criar obstáculos ao processo e as dificuldades jurídicas geradas pela ausência de previsão legislativa regulando as soluções em ODR. Em relação às dificuldades, o autor reforça e justifica a terminologia escolhida por entender que elas podem ser superadas ou diminuídas no decorrer da prática e com o desenvolvimento de experiências, tecnologias e leis apropriadas.

Quanto à economia financeira, Cortés (2011) argumenta que os modelos de ODR oferecem custo inferior aos das soluções offline de conflitos, por se tratar de um formato mais informal, que possibilita o acesso do usuário em qualquer lugar, sobretudo nas lides envolvendo partes que possuem domicílio em comarcas distintas, que não necessitarão arcar com custos de viagem para audiências e/ou sessões de mediação ou conciliação. De forma complementar à economia financeira, Cortés (2011) cita, ainda, como vantagem a economia de tempo. As características das TICs ofereceriam ainda o benefício de não depender do horário de funcionamento dos tribunais.

Para a própria estrutura do Poder Judiciário, estas soluções mostram vantagens adicionais na medida em que poderiam eliminar um número elevado de potenciais processos, antes mesmo do seu nascimento, ou logo no início do conflito, economizando o valor movimentado pela máquina estatal para prover uma resposta às partes. Some-se a isso, o fato das soluções em ODR poderem eliminar as audiências de conciliação, por exemplo, o que asseguraria um aproveitamento mais eficiente do trabalho dos servidores, com a eliminação de uma lista de expedientes e pequenos atos de movimentação processual.

Cortés (2011), ao defender a conveniência do procedimento como uma vantagem da ODR, reduz a importância, assim como Katsh (2012), da teoria do contato, que valoriza a interação F2F, afirmando que a comunicação remota, possui vantagens como uma preparação antecipada para a elaboração da melhor resposta possível e um pensamento e análise mais profunda durante a comunicação.

Não obstante, Cortés (2011) reconhece algumas desvantagens geradas pela ausência de contato F2F. A distância impossibilitaria a identificação das formas não-verbais de comunicação, como a 
linguagem corporal e expressões faciais. Alguns artifícios tecnológicos, contudo, podem ser utilizados para mitigar estas desvantagens, como a vídeo-conferência.

A interação entre as partes por meio de texto também oferece a vantagem da troca de mensagens assíncrona, o que possibilita que ambas as partes pensem de forma mais cuidadosa o texto que enviarão para o interlocutor, buscando racionalizar mais a mensagem, realizando, inclusive, uma autoanálise das emoções estimuladas pelo conflito.

Sobre o uso da tecnologia, Cortés (2011) cita as divergências em potência de maquinário e habilidade tecnológica entre indivíduos e locais, excluindo determinados segmentos sociais do processo. A necessidade de criação de ferramentas de ODR surgiu em decorrência, principalmente, dos conflitos nos quais as partes residem em cidades e, por vezes, países diferentes. Essa variedade de locais pode interferir na qualidade tecnológica do maquinário ou mesmo na conexão à internet a serem utilizados por uma ou outra parte. Da mesma forma, os indivíduos possuem aptidões para o manuseio de dispositivos digitais em diferentes graus, o que poderia ocasionar desvantagem à parte menos habilidosa.

Essa preocupação parece pouco relevante, todavia, ao se verificar que as ferramentas de ODR disponibilizadas no mercado funcionam por sistemas de troca de mensagens de texto, o que não demanda alta qualidade de conexão à internet, nem grande modernidade do maquinário. Quanto à habilidade das partes para lidar com os recursos tecnológicos, nos sistemas baseados em trocas de mensagens de texto, normalmente há prazo hábil para que se envie as respostas necessárias, assim a parte menos habilidosa possui tempo para se ambientar com a ferramenta ou para requerer auxílio.

Não há dúvida, que este é um obstáculo real a ser enfrentado pelo modela da ODR, sobretudo quando se trata de um país como o Brasil, que possui taxas de desigualdade social elevadas, apenas metade da população possui acesso à internet (SECOM, 2014) e onde ainda há significativa parte da população vivendo em zona rural. Contudo, o déficit tecnológico tende a se reduzir com a acelerada expansão da internet, em particular como o uso de dispositivos móveis.

A ferramentas de ODR incorporam ainda, como aspecto positivo, as qualidades dos MASCs na medida em que oferecem aos envolvidos maior controle e participação em todo o processo decisório. Warat (1977, p. 6) ressalta a importância desta perspectiva quando se observam os meios alternativos de solução de conflito, ao afirmar que, ao contrário da litigância ou da arbitragem, em que uma decisão é imposta às partes, a mediação (e a conciliação):

[...] [son procesos] de autocomposicion en la medida en que son las mismas partes de un conflicto las que tratan de llegar a la produccion, con el otro adversario, de una diferencia que pueda recomponer, a través de uns mirada interior, los ingredientes afectivos, juridicos, pratrimoniales o de otros tipos y generar, así, lo nuevo en el conflicto.

Por fim, vale salientar a ausência de um marco legal apto a guiar as experiências de ODR no Brasil e no mundo. A carência regulamentação permite a exploração de novas fronteira e técnicas, sem grandes amarras jurídicas, todavia gera insegurança para alguns agentes, em especial no setor 
públicos. Cortés (2011) ressalta a dificuldade gerada pela ausência de corpo legislativo que regule os parâmetros e utilização das ODR, sobretudo no caso de adoção destas soluções pelo Poder Judiciário.

Neste contexto, pode-se afirmar a preponderância das vantagens às dificuldades, não só pelo número superior daquelas, mas sobretudo pela possibilidade de mitigação ou superação das dificuldades enumeradas. Inúmeras vantagens e dificuldades ainda surgirão durante a evolução contínua das ODR, uma vez que o conceito é novo e se encontra e plena formação. No entanto, num cenário de rápida transformação social geral pelas novas tecnologias, observa-se na ODR um candidato com grande potencial modificar e renovar as formas tradicionais de solução de conflitos dentro e fora do Judiciário.

\section{DESAFIOS E PERSPECTIVAS PARA ODR}

As possibilidades oferecidas pelas TICs possuem poder cada vez maior de manipular e, em certo grau, mesmo remover os obstáculos de tempo e espaço (KATSH, 2012). As transformações tecnológicas surgem como um dos aspectos mais relevantes na aceleração das transformações e adaptações das sociedades na contemporaneidade. Wing e Rainey (2012) reiteram, todavia, que a Internet e telefones celulares são apenas as tecnologias mais recentes numa longa linhagem de tecnologias que transformaram radicalmente as formas de interação social.

Da mesma forma acontece com os conflitos em si e, consequentemente, com suas soluções. As soluções em ODR surgiram e, até o momento, ainda são consideradas, uma extensão dos MASCs (arbitragem, conciliação, mediação e negociação), ou seja, uma nova plataforma para que os MASCs sejam realizados. No entanto, Katsh (2012) acredita que aquelas podem se afastar conceitualmente destas, da mesma forma que os MASCs se afastaram conceitualmente da litigância nos tribunais.

Wing e Rainey (2012) consideram que a humanidade sobreviverá a "Era da Internet" de maneiras que não podemos prever. No entanto, Katsh (2012) considera que algumas previsões são possíveis para o futuro das ODR, antecipando que estas oferecerão avanço significativo no processamento de informações, mais do que nas soluções tecnológicas em si. O autor entende que as ODR podem se desenvolver numa direção ainda indistinta, em que o papel da informação será mais valorizado na prevenção de conflitos, mais do que simplesmente na sua solução. A "quarta parte", desta forma, deixaria de ser mero assistente da "terceira parte", imparcial, a passaria a funcionar como uma nova personalidade facilitadora da negociação, com princípios e funções próprios a sua atuação.

Katsh (2012) ainda salienta a importância que os modelos de ODR podem ter para os tribunais, enquanto política pública para o Poder Judiciário, de forma a aprimorar a prestação jurisidicional ${ }^{14}$.

Wing e Rainey (2012) reportam-se à dificuldade exposta por Cortés (2011) decorrente da ausência do contato F2F, declarando a necessidade de pesquisa neste campo e questionando que

\footnotetext{
${ }^{14}$ No Brasil, o Conselho Nacional de Justiça vislumbrou esta oportunidade e anunciou, no início de 2016, o sistema de Mediação Digital. A criação do sistema está prevista no artigo 18, da Resolução no 125, emendada em março de 2016.
}

Revista do Direito [ISSN 1982-9957]. Santa Cruz do Sul, v. 3, n. 50, p. 53-70, set./dez. 2016. https://online.unisc.br/seer/index.php/direito/index 
solução online poderia ser encontrada para facilitar a leitura de linguagem não verbal em comunicação remota. Nesse sentido, os autores direcionaram a importância do estudo em ODR para a busca dessa solução, apontando esta como um dos próximos grandes desafios para a evolução das ODR.

Por fim, Cortés (2011) estabelece que as soluções em ODR não são mais "ficção científica", já são utilizadas com sucesso por empresas de e-commerce e possuem potencial para se tornar a forma principal de solução de determinados tipos de conflito. Os próximos passos para esta tecnologia, afirma o autor, deverão ser dados pelos Estados e organizações regionais, como a União Europeia, que já estabeleceu uma plataforma de ODR para solução de conflitos consumeristas transnacionais (EUROPEAN COMISSION, online; UNIÃO EUROPÉIA, 2013). O grande desafio neste momento seria, para ele, promover o conhecimento da sociedade acerca desta solução e construir confiança e credibilidade para as iniciativas estatais, assim como fortalecer a previsão legislativa para adoção das $O D R^{15}$.

A experiência consolidada de sistemas baseados em ODR na esfera privada oferecem subsídios importantes para essa nova etapa de aplicação das TICs na esfera judicial. Para além do uso de computadores, redes e da virtualização do processo, sobressai o desafio de construir uma nova experiência de tratamento dos conflitos que efetivamente se aproprie da dinâmica da interação em redes sociais e explore a popularização dos usos da internet em dispositivos móveis. Trata-se de um desafio de grande complexidade, pois implica em olhar o conflito e sua solução por um novo prisma.

\section{CONSIDERAÇÕES FINAIS}

As ferramentas de ODR apresentam uma série de obstáculos a serem superados para que alcancem seu máximo potencial. Dentre estes desafios, pode-se citar a ausência de contato face-aface, uma vez que as partes interagem por meio de dispositivo digital. Estas características acarretam dificuldades na compreensão de sentimentos e na empatia, tão fundamental aos MASCs.

No entanto, alguns aspectos positivos advindos das plataformas de troca de mensagens de texto, que se apresentam como majoritárias no mercado, podem ser percebidas. Cita-se como vantagens a possibilidade de comunicação assíncrona, o que, além de representar a óbvia vantagem de economia de tempo, também permite às partes maior tempo de análise daquilo que se pretende falar. Em decorrência disso, assegura-se maior poder de decisão sobre o que se quer revelar e sobre que tipo de linguagem se pretende adotar.

Além desse desafio, menciona-se também o possível desequilíbrio em potência de maquinário e familiaridade com dispositivos digitais entre as partes (CORTÉS, 2011). Nesse sentido, entende-se que o desequilíbrio em potência de maquinário não representa um obstáculo real à concretização adoção das ferramentas de ODR, uma vez que não há necessidade de grande

\footnotetext{
${ }^{15}$ Estudos pioneiros sobre "Online Dispute Resolution” no Brasil foram realizados por Fernando Sérgio Tenório de Amorim (2016). Em artigo intitulado "A resolução online de litígios (ODR) de baixa intensidade: perspectivas para a ordem jurídica brasileira" o autor relata experiências internacionais de aplicação da ODR, seus desafios e importantes obstáculos normativos.
}

Revista do Direito [ISSN 1982-9957]. Santa Cruz do Sul, v. 3, n. 50, p. 53-70, set./dez. 2016. https://online.unisc.br/seer/index.php/direito/index 
capacidade de hardware e software para que uma plataforma de ODR funcione de maneira satisfatória.

A familiaridade das partes para lidar com dispositivos digitais e o acesso à internet representa um problema especialmente importante no Brasil. O país ainda sofre de grandes disparidades sociais e apenas metade da população afirma ter acesso à internet. Contudo, tendo em vista o acelerado crescimento da difusão da utilização da internet, em especial com uso de dispositivos móveis, há uma tendência a mitigação do déficit tecnológico.

A falta de marcos legais claros gera relativa insegurança, todavia não impediu o avanço das experiências de ODR no setor privado. O maior problema relacionado a esta carência ocorre no setor público, vinculado a procedimentos mais rígidos e limitados quanto ao tratamento dos conflitos. A dificuldade poderá se reduzir com o avanço de políticas governamentais baseadas nos usos da ODR e com a expansão acelerada da internet e demais formas de interação por meio das novas tecnologias da informação e da comunicação.

Os desafios elencados não superam as vantagens da economia financeira e de tempo que as partes gozarão, na medida em que não precisarão arcar com a despesa de viagens, comparecer a audiências, tampouco (em muitos casos) contratar advogados. O maior controle das partes sobre a tomada de decisão e a comunicação assíncrona, característica peculiar às ODRs, são aspectos únicos, que não se apresentam de forma tão pronunciada em nenhum outro MASC e representam potencial inigualável de mudança de cultura e empoderamento social para que os indivíduos passem a buscar a solução de seus conflitos por meio de procedimentos dialogados.

\section{REFERÊNCIAS}

AMORIM, Fernando Sérgio Tenório de. A Resolução Online de Litígios (ODR) de Baixa Intensidade e seus Reflexos no Direito Internacional Privado: Uma Análise da Normatividade Polissêmica das Redes Numéricas. Revista Internacional Consinter de Direito, Ano 2, Volume 2, São Paulo, 2016, online. DOI: 10.19135/revista.consinter.00002.14.

BENYEKHLEF, Karim; GÉLINAS, Fabien. Online Dispute Resolution. Lex Electronica, Montréal, v. 10, n. 2, p.1-126, ago. $2005 . \quad$ Disponível em: <http://poseidon01.ssrn.com/delivery.php?ID=85700507103102600508907211311612100004003202 003100305408511811509608100402311200406405411400103706210401403001000211510206602 003301601008105911202400408707711306508608208402409509300308401612406906709209010 0083080068031075022075124080116111067000067\&EXT=pdf>. Acesso em: 10 abr. 2016.

BAUMAN, Zygmunt. Modernidade Líquida. Tradução: Plínio Dentzien. Rio de Janeiro: Zahar, 2003. $258 p$.

CASTELLS, Manuel. Galáxia da Internet: Reflexões sobre a internet, os negócios e a sociedade. Rio de Janeiro: Zahar, 2003.

COHEN-ALMAGOR, Raphael. Internet History. In: LUPPICINI, Rocci. Moral, Ethical and Social Dilemmas in the Age of Technology:Theories and Practice. Hershey: Information Science Reference, 2013. p. 19-39.

CORTÉS, Pablo. Online Dispute Resolution for Consumers in the European Union. New York: Routledge, 2011. Disponível em: <http://www.oapen.org/download?type=document\&docid=391038>. Acesso em: 15 abr. 2016. 
EUROPEAN COMISSION. Online Dispute Resolution. Disponível em: $<$ https://webgate.ec.europa.eu/odr/main/?event=main.home.show>. Acesso em: 28 set. 2016.

FREIRE, Geovana Maria Cartaxo de Arruda. Ciberdemocracia no Judiciário: Uso de Mapas como Política de Virtualização. 2014. 351 f. Tese (Doutorado) - Curso de Direito, Departamento de Centro de Ciências Jurídicas, Universidade Federal de Santa Catarina, Florianópolis, 2014.

GELLMAN, Robert. History of Virtual Magistrate. In: DISPUTE RESOLUTION CONFERENCE, 1996, Washington D.C. Disponível em: <http://www.umass.edu/dispute/ncair/>. Acesso em: 09 abr. 2016.

GOLDSMITH, Jack; LESSIG, Lawrence. Gounding the Virtual Magistrate. In: DISPUTE RESOLUTION CONFERENCE, 1996, Washington D.C. Disponível em: <http://www.umass.edu/dispute/ncair/>. Acesso em: 09 abr. 2016.

GOODMAN, Joseph W.. The Pros and Cons of Online Dispute Resolution: An Assessment of CyberMediation Websites. Duke Law \& Technology Review, Durham, v. 2, n. 1, p.0-0, ago. 2003. Disponível em: <http://scholarship.law.duke.edu/dltr/vol2/iss1/2>. Acesso em: 20 abr. 2016.

HAUBEN, Michael; HAUBEN, Rhonda. Netizens: On the history and impact of Usenet and the Internet. Los Alamitos: leee Computer Society Press, 1997.

KATSH, Ethan; RIFKIN, Janet; GAITENBY, Alan. E-commerce, e-disputes and e-dispute resolution: In the shadow of "eBay law". Ohio State Journal On Dispute Resolution, Ohio, v. 15, n. 3, p.705-734, set. 2000. Disponível em: <http://www.umass.edu/cyber/katsh.pdf>. Acesso em: 20 abr. 2016.

KATSH, Ethan e RIFIKIN, Janet. Online Dispute Resolution: resolving conflicts in cyberspace. San Francisco: Jossey-Bass, 2001.

KATSH, Ethan. Dispute Resolution WIthout Borders: Some implications for the Emergence of Law in Cyberspace. First Monday,Chicago, v. 11, n. 2, fev. 2006. Disponível em: <http://ojs-prodlib.cc.uic.edu/ojs/index.php/fm/article/view/1313/1233>. Acesso em: 10 abr. 2016.

KATSH, Ethan. ODR: a look at history. In: WAHAB, Mohamed S. Abdel; KATSH, Ethan e RAINEY, Daniel (Eds). Online dispute resolution: theory and practice. A treatise on technology and dispute resolution. The Hague: Eleven International, 2012.

KLEINROCK, Leonard. An early history of the Internet: history of communications. leee Communications Magazine, Bridgewater, v. 0, n. 0, p.26-36, ago. 2010. Disponível em: $<$ http://ieeexplore.ieee.org/xpls/icp.jsp?arnumber=5534584>. Acesso em: 12 abr. 2016.

LEINER, Barry M. et al. The past and future History of the Internet. Communications of Acm, Online, v. 40, n. 2, p.102-108, fev. 1997. Disponível em: <https://www.semanticscholar.org/paper/ThePast-and-Future-History-of-the-Internet-Leiner-

Cerf/625d33d39ceb2abc31de96ad8f25988c056df230/pdf>. Acesso em: 08 abr. 2016.

LEMOS, André. Cidade Digital: Portais, Inclusão e Redes no Brasil. EDUFBA: Salvador, 2007.

LESSIG, Lawrence. Code: The new law of internet. 2. ed. New York: Basic Books, 2006.

LEVIN, Diane J. Cubersettle makes the case for resolving disputes online. Mediation Channel. Boston, p. 0-0. fev. 2008. Disponível em: <https://mediationchannel.com/2008/02/20/cybersettlemakes-the-case-for-resolving-disputes-online/>. Acesso em: 18 abr. 2016.

LÉVY, Pierre. Cibercultura. São Paulo: 34, 1999.

LÉVY, Pierre. O que é Virtual? 2. ed. São Paulo: 34, 2011.

O'REILLY, Tim; BATTELLE, John. Web Squared: Web 2.0 Five Years On. In: WEB 2.0 SUMMIT, 1., 2009, San Francisco. Special Report. San Francisco: Web 2.0 Summit, 2009. p. 1 - 13. Disponível em: <http://assets.en.oreilly.com/1/event/28/web2009_websquared-whitepaper.pdf>. Acesso em: 14 abr. 2016.

RULE, Colin. Online Dispute Resolution for Business: B2B, E-Commerce, Consumer, Employment, Insurance and Other Commercial Conflicts. San Francisco: Jossey-bass, 2002. 
SALES, Lilia Maia de Morais. Mediare: Um guia prático para mediadores. Fortaleza: Expressão, 2004.

SALES, Lilia Maria de Morais. A evolução da mediação através dos anos - Aprimoramentos das discussões conceituais. In BRAGA NETO, Adolfo; SALES, Lilia Maria de Morais (coords.). Aspectos atuais sobre a mediação e outros métodos extra e judiciais de resolução de conflitos. Rio de Janeiro: GZ Ed., 2012.

SANDER, Frank E. A.. Future of ADR: The Earl F. Nelson Memorial Lecture. Journal of Dispute Resolution. Columbia, p. 3-10. ago. 2000. Disponível em: <http://scholarship.law.missouri.edu/jdr/vol2000/iss1/5>. Acesso em: 20 abr. 2016.

SMARTSETTLE. SmartSettle: Changing the way world negotiate. 2016. Disponível em: $<w w w . s m a r t s e t t l e . c o m>$. Acesso em: 15 maio 2016.

THIESSEN, Ernest M.; FRASER, Ken. Mobile ODR with SmartSettle. In: UNECE FORUM ON ODR, 0., 2003, Genebra. Proceedings... . 2003. p. 1 - 20. Disponível em: <https://www.smartsettle.com/smart2011/wp-content/uploads/2011/03/Mobile-ODR-with-

Smartsettle.pdf>. Acesso em: 10 abr. 2016.

UNIÃO EUROPÉIA. Regulamentos (UE) No524/2013 DO PARLAMENTO EUROPEU E DO CONSELHO de 21 de maio de 2013. Sobre a resolução de litígios de consumo em linha, que altera o Regulamento (CE) no. 2006/2004 e a Diretiva 2009/22/CE (Regulamento RLL). Disponível em: < http://eur-lex.europa.eu/legalcontent/PT/TXT/PDF/?uri=CELEX:32013R0524\&from=EN>. Acesso em: 28 set. 2016.

VIÑALS, Immaculada Barral. Consumidores, online dispute resolution y reclamaciones de pequeña cuantía. Democracia Digital e Governo Eletrônico, Florianópolis, v. 1, n. 10, p.394-415, jul. 2014. Disponível em: <http://buscalegis.ufsc.br/revistas/index.php/observatoriodoegov/article/view/34352/33200>. Acesso em: 29 abr. 2014.

WARAT, L. A. Mediación, el derecho fuera de las normas: para una teoría no normativa del conflicto. Scientia luris - Revista do Curso de Mestrado em Direito Negocial da Universidade Estadual de Londrina, v. 1, n. 1, p. 3-18, jul./dez. 1977.

WING, Leah e RAINEY, Daniel. Online dispute resolution and the development of theory. In: WAHAB, Mohamed S. Abdel; KATSH, Ethan e RAINEY, Daniel (Eds). Online dispute resolution: theory and practice. A treatise on technology and dispute resolution. The Hague: Eleven International, 2012.

\section{COMO CITAR ESSE DOCUMENTO:}

LIMA, Gabriela Vasconcelos; FEITOSA, Gustavo Raposo Pereira. Online dispute resolution (ODR): a solução de conflitos e as novas tecnologias. Revista do Direito, Santa Cruz do Sul, v. 3, n. 50, p. 5370, set. 2016.2 ISSN 1982-9957. Disponível em: $<$ https://online.unisc.br/seer/index.php/direito/article/view/8360>. Acesso em: doi:http://dx.doi.org/10.17058/rdunisc.v3i50.8360. 